\title{
DESIGN AND EVALUATION OF INTRAGASTRIC BUOYANT TABLETS OF VENLAFAXINE HYDROCHLORIDE
}

\author{
RADHIKA PR*, NISHALA N, KIRUTHIKA M, SREE ISWARYA S
}

Department of Pharmaceutics, J.K.K. Nattraja College of Pharmacy, Namakkal - 638 183, Tamil Nadu, India.

Email: radhi_kannan2005@yahoo.co.in

Received: 05 January 2017, Revised and Accepted: 13 February 2017

\section{ABSTRACT}

Objective: The present study was undertaken to prolong the release of orally administered drug. The aim is to formulate, develop, and evaluate the intragastric buoyant tablets of venlafaxine hydrochloride, which releases the drug in a sustained manner over a period of $12 \mathrm{hrs}$. Different formulations were formulated using the polymers Carbopol 934 P, xanthan gum, hydroxypropyl methylcellulose (HPMC K100M) with varying concentration of drug: Polymer ratio of 1:1,1:1.5, 1:2, in which sodium bicarbonate acts as gas generating agent, and microcrystalline cellulose as a diluent.

Methods: The tablets were prepared by direct compression and evaluated for tablet thickness, weight variation, tablet hardness, friability, in vitro buoyancy test, in vitro drug release and Fourier transform infrared spectroscopy. Formulations were evaluated by floating time, floating lag time and in vitro drug release. Dissolution profiles were subjected for various kinetic treatments to analyze the release pattern of drug.

Results: It was found that drug release depends on swelling, erosion, and diffusion, thus following the non-Fickian/anomalous type of diffusion. Formulation F8 was considered as an optimized formulation for gastro retentive floating tablet of venlafaxine hydrochloride. The optimized formulation showed sustained drug release and remained buoyant on the surface of the medium for more than $12 \mathrm{hrs}$. As the concentration of HPMC $\mathrm{K} 100 \mathrm{M}$ increases in the formulation the drug release rate was found to be decreased. The optimized formulation was subjected for the stability studies and was found to be stable as no significant change was observed in various evaluated parameters of the formulation.

Conclusion: It can be concluded that floating drug delivery system of venlafaxine hydrochloride can be successfully formulated as an approach to increase gastric residence time, thereby improving its bioavailability.

Keywords: Venlafaxine hydrochloride, Intragastric buoyant, Floating drug delivery systems, Hydroxypropyl methyl cellulose K100M, Carbopol 934 P, Xanthan gum.

(C) 2017 The Authors. Published by Innovare Academic Sciences Pvt Ltd. This is an open access article under the CC BY license (http://creativecommons. org/licenses/by/4. 0/) DOI: http://dx.doi.org/10.22159/ajpcr.2017.v10i5.16948

\section{INTRODUCTION}

Oral controlled drug delivery system is useful to maintain therapeutically effective plasma drug concentration levels for a longer duration thereby reducing the dosing frequency and to minimize fluctuations in the plasma drug concentration at the steady state by delivering the drug in a controlled and reproducible manner [1]. Moreover, it is easy for administration, no patient compliances, and flexibility in the formulation. Many studies have been performed concerning the sustained release dosage form of drug, which have aimed at the prolongation of gastric emptying time, i.e., gastro retentive drug delivery system, which will provide as with new and important therapeutic options, which utilize several approaches such as intragastric floating system [2], highdensity system [3], mucoadhesive system [4], and super porousbiodegradable hydrogel systems [5]. In gastro retentive system, drugs can remain in the gastric region for several hours and significantly prolong the gastric resistance time of drugs. Prolonged gastric retention improves bioavailability, reduces drug waste and improves solubility of drugs that are less soluble in a high $\mathrm{pH}$ environment. It has applications also for long drug delivery to the stomach and proximal small intestines [6]. Gastro retention helps to provide better availability of new products with new therapeutic possibility and substantial benefits for patients [7]. Drugs that are required to be formulated into gastro-retentive dosage forms include drugs acting locally and primarily absorb in the stomach, drugs that are orally soluble at an alkaline $\mathrm{pH}$, those with a narrow window of absorption, drugs absorbed rapidly from gastrointestinal tract (GIT) and drugs that degrade in colon [8].
Different methods are used depending on the mechanism of buoyancy in the development floating drug delivery system (FDDS). They are effervescent and non-effervescent system [9]. The most commonly used excipients in non-effervescent FDDS are gel forming on highly swellable cellulose type hydrocolloids, polysaccharides and matrix forming polymers such as polycarbonate, polyacrylate, polymethacrylate, and polystyrene. The floating dosage forms involve intimate mixing of drug with a gel forming hydrocolloid, which swells in contact with gastric fluid after oral administration and maintains a relative integrity of shape and bulk density of less than unity with in the outer gelatinous barrier [10]. The air trapped by the swollen polymer confers buoyancy to these dosage forms and gel structure act as a reservoir for sustained drug release [11]. The effervescent buoyant delivery system utilizes matrices prepared with swellable polymers such as Methocelor polysaccharides (chitosan) and effervescent components such as sodium bicarbonate and citric or tartaric acid [12] or matrices containing chambers of liquid that gasify at body temperature [13-15]. They are fabricated in such a way that on arrival in the stomach, carbon dioxide is liberated by the acidity of the gastric contents and entrapped in a gellified hydrocolloid which produces an upward movement of the dosage form and maintains its buoyancy.

Venlafaxine hydrochloride is a unique anti-depressant and is referred to as a serotonin-nor epinephrine-dopamine reuptake inhibitors [16]. Venlafaxine hydrochloride helps in releasing a small quantity of drug, advantage for treating a depressive disorder. It has a short bioavailability of $12.6 \%$ and biological half-life of 5 hrs. Therefore, the frequent administration is necessary to maintain the therapeutic concentration of the drug with in the therapeutic index. To overcome the drawback, 
the present study, gastric retentive controlled release dosage form of the drug in the form of tablet was formulated [17] with Carbopol 934P, xanthan gum, and hydroxypropyl methylcellulose (HPMC K100M) with varying concentration of drug: Polymer ratio $(1: 1,1: 1.5,1: 2)$.

The aim of the present study was not only preparing intragastric buoyant tablet but also to release the drug in controlled system. Polymers were added in different concentrations with varying amount of retardant material and investigated the release profile of the drug by in vitro dissolution study to achieve an extended retention in the upper GIT, to enhance the absorption and improve the bioavailability.

\section{MATERIALS AND METHODS}

Materials

Venlafaxine hydrochloride and HPMC K100 M was procured as a gift sample from Aurobindo Pharma, Carbopol 934P and xanthan gum from Himedia Laboratories, microcrystalline cellulose and magnesium stearate from SD Fine Chemicals.

\section{Methods}

\section{Preparation of venlafaxine hydrochloride floating tablets}

Floating matrix tablet were prepared using direct compression technique [18-21] with the use of a different polymer with varying concentration $(1: 1,1: 1.5,1: 2)$, i.e., drug to polymer ratio as shown in Table 1. All polymer and drug were passed through sieve no.80 separately. Then drug was mixed for 10 minutes with polymers and other excipients in weight proportion as mentioned in the table. The powder blend was then lubricated by magnesium stearate and talc. Finally, this lubricated blend was subjected to compression into tablets using $10-\mathrm{mm}$ flat-face on a 16 stationary rotary punching tablet machine. The composition of all the formulations is given in Table 1.

\section{Evaluation of powder blend}

The powder blends of all formulation were evaluated for bulk density, tapped density [22], angle of repose [23], Carr's compressibility index [24], and Hausner ratio [25].

\section{Evaluation of tablets}

The prepared intragastric buoyant tablets were subjected to weight variation, hardness by using Monsanto hardness tester, thickness using Vernier Calliper, friability using Roche friabilator and drug content $[26,27]$

\section{Swelling index}

The swelling of tablet involves the absorption of a liquid resulting in an increase in weight and volume. Liquid uptake by the particle may be due to saturation of capillary spaces within the particles. The liquid enters the particles through pores and bind to a large molecule, breaking the hydrogen bond, and resulting in the swelling of particle $[28,29]$. The extent of swelling can be measured in terms of \% weight gain by the tablet. The measurement of swelling rate of the floating matrix tablet was carried to gain, insight the observed phenomenon of drug release with the rates of polymer hydration. Swelling index of the dosage form is conducted using USP dissolution apparatus-II in $900 \mathrm{ml}$ of $0.1 \mathrm{~N}$ hydrochloric acid $(\mathrm{HCl})$ which is maintained at $37 \pm 0.5^{\circ} \mathrm{C}$, rotated at
$50 \mathrm{rpm}$. At selected regular intervals, the tablet was withdrawn, and the excess water was blotted with tissue paper, and the swelling index was calculated using following formula.

$\%$ Swelling index $=\left\{\left(\mathrm{W}_{\mathrm{t}}\right)-\left(\mathrm{W}_{0}\right) /\left(\mathrm{W}_{0}\right)\right\} \times 100$

Where, $\mathrm{W}_{\mathrm{t}}=$ Weight of the swollen tablet, $\mathrm{W}_{0}=$ Initial weight of the tablet.

\section{Buoyancy studies}

The in vitro buoyancy (floating behavior) [30] of the tablets was determined by floating lag time (FLT). The tablets were placed in $100 \mathrm{ml}$ beaker containing $0.1 \mathrm{~N} \mathrm{HCl} \mathrm{(pH} \mathrm{1.2).} \mathrm{The} \mathrm{time} \mathrm{taken} \mathrm{by} \mathrm{the}$ tablet to reach the surface and float was determined by the FLT [31]. The duration of the time the dosage form constantly remained on the surface was determined as of total floating time (TFT).

\section{Uniformity of drug content}

The drug content was performed to check the dose uniformity in the formulation. Randomly 10 tablets were weighed and powdered. A quantity equivalent to $100 \mathrm{mg}$ of venlafaxine hydrochloride was added into a $100 \mathrm{ml}$ volumetric flask and dissolved in $0.1 \mathrm{~N} \mathrm{HCI}$, shaken for 10 minutes and made up to the volume with $0.1 \mathrm{~N} \mathrm{HCl}$. After suitable dilutions, the drug content was determined by ultraviolet (UV) spectrophotometer at $224 \mathrm{~nm}$ against blank.

\section{In vitro release studies for floating tablets}

The release rate of the drug venlafaxine hydrochloride floating tablets was determined using USP Type II dissolution apparatus. The dissolution was carried out using $900 \mathrm{ml}$ of simulated gastric fluid $(\mathrm{pH} 1.2)$ as dissolution media, maintained at $37 \pm 0.1^{\circ} \mathrm{C}$ and rotated at $50 \mathrm{rpm}$ for $12 \mathrm{hrs} .5 \mathrm{ml}$ of the samples were withdrawn at suitable time intervals, and the samples were replaced with fresh dissolution medium [16,32]. The samples were filtered through $0.45 \mu \mathrm{m}$ membrane filter and diluted if necessary. Absorbances of these solutions were measured at $224 \mathrm{~nm}$ using UV-visible spectrophotometer. Samples were assayed in triplicate.

\section{Mechanism of drug release}

To analyze the mechanism of drug release rate kinetics from the intragastric buoyant tablets, the obtained data were fitted into zero order, first order, Higuchi, and Koresmeyer-Peppas release model [33-35].

\section{Stability studies}

Stability studies of pharmaceutical products were done as per ICH guidelines. These studies are designed to increase the rate of chemical or physical degradation of the drug substance or product using exaggerated storage conditions. The optimized formulation was stored at different storage conditions at elevated temperatures such as $25^{\circ} \mathrm{C} \pm 2^{\circ} \mathrm{C} / 60 \% \pm 5 \% \quad \mathrm{RH}, \quad 30^{\circ} \mathrm{C} \pm 2^{\circ} \mathrm{C} / 65 \% \pm 5 \% \quad \mathrm{RH}$, and $40^{\circ} \mathrm{C} \pm 2{ }^{\circ} \mathrm{C} / 75 \% \pm 5 \% \mathrm{RH}$ for 90 days. The samples were withdrawn at intervals of 30 days and checked for physical changes, hardness, friability, drug content, FLT, and percentage drug release.

\section{RESULTS AND DISCUSSION}

To check the integrity of the drug in the formulation, Fourier transform infrared (FTIR) spectra of pure drug venlafaxine hydrochloride,

Table 1: Composition of floating tablets of venlafaxine hydrochloride average weight of tablets $\mathbf{3 3 0} \mathrm{mg}$

\begin{tabular}{|c|c|c|c|c|c|c|c|c|c|}
\hline Ingredient's (mg/tablet) & F1 & F2 & F3 & F4 & F5 & F6 & F7 & F8 & F9 \\
\hline Venlafaxine $\mathrm{HCl}$ & 75 & 75 & 75 & 75 & 75 & 75 & 75 & 75 & 75 \\
\hline Carbopol 934 & 75 & 112.5 & 150 & - & - & - & - & - & - \\
\hline Xanthan gum & - & - & - & 75 & 112.5 & 150 & - & - & - \\
\hline HPMC K100M & - & - & - & - & - & - & 75 & 112.5 & 150 \\
\hline MCC & 95 & 57.5 & 20 & 95 & 57.5 & 20 & 95 & 57.5 & 20 \\
\hline Sodium bicarbonate & 70 & 70 & 70 & 70 & 70 & 70 & 70 & 70 & 70 \\
\hline Magnesium stearate & 5 & 5 & 5 & 5 & 5 & 5 & 5 & 5 & 5 \\
\hline
\end{tabular}

HPMC: Hydroxy propyl methyl cellulose, MCC: Micro crystalline cellulose, HCl: Hydrochloric acid 
Table 2: Evaluation parameters of powder blend

\begin{tabular}{llll}
\hline Formulation & $\begin{array}{l}\text { Angle of } \\
\text { repose }\end{array}$ & $\begin{array}{l}\text { Bulk } \\
\text { density (gm/cc) }\end{array}$ & $\begin{array}{l}\text { Tapped } \\
\text { density (gm/cc) }\end{array}$ \\
\hline F1 & $29^{\circ} 11 \pm 0.1$ & $0.36 \pm 0.004$ & $0.41 \pm 0.018$ \\
F2 & $30^{\circ} 31 \pm 0.2$ & $0.37 \pm 0.001$ & $0.44 \pm 0.017$ \\
F3 & $32^{\circ} 11 \pm 0.5$ & $0.38 \pm 0.005$ & $0.44 \pm 0.004$ \\
F4 & $30^{\circ} 61 \pm 0.3$ & $0.35 \pm 0.005$ & $0.41 \pm 0.003$ \\
F5 & $32^{\circ} 81 \pm 0.5$ & $0.34 \pm 0.004$ & $0.40 \pm 0.018$ \\
F6 & $33^{\circ} 81 \pm 0.1$ & $0.35 \pm 0.002$ & $0.42 \pm 0.001$ \\
F7 & $28^{\circ} 11 \pm 0.7$ & $0.35 \pm 0.002$ & $0.40 \pm 0.005$ \\
F8 & $28^{\circ} 51 \pm 0.3$ & $0.36 \pm 0.003$ & $0.41 \pm 0.002$ \\
F9 & $31^{\circ} 21 \pm 0.1$ & $0.36 \pm 0.005$ & $0.42 \pm 0.004$ \\
\hline
\end{tabular}

Table 3: Evaluation parameters of formulations

\begin{tabular}{|c|c|c|c|c|c|}
\hline Formulation & Thickness (mm) & Hardness $\left(\mathrm{kg} / \mathrm{cm}^{2}\right)$ & Friability (\%) & Weight variation (mg) & Drug content (\%) \\
\hline F1 & $3.76 \pm 0.04$ & $5.33 \pm 0.02$ & $0.65 \pm 0.07$ & $331.2 \pm 1.3$ & $98.06 \pm 0.002$ \\
\hline F2 & $3.68 \pm 0.07$ & $5.61 \pm 0.05$ & $0.59 \pm 0.09$ & $330.7 \pm 1.4$ & $98.39 \pm 0.001$ \\
\hline F3 & $3.62 \pm 0.02$ & $5.44 \pm 0.03$ & $0.53 \pm 0.05$ & $331.5 \pm 1.7$ & $97.22 \pm 0.001$ \\
\hline F4 & $3.71 \pm 0.04$ & $5.48 \pm 0.01$ & $0.54 \pm 0.11$ & $330.2 \pm 2.1$ & $99.02 \pm 0.001$ \\
\hline F5 & $3.67 \pm 0.09$ & $5.86 \pm 0.04$ & $0.47 \pm 0.08$ & $329.8 \pm 2.3$ & $97.18 \pm 0.000$ \\
\hline F6 & $3.63 \pm 0.11$ & $6.14 \pm 0.02$ & $0.47 \pm 0.12$ & $331.3 \pm 2.1$ & $97.56 \pm 0.001$ \\
\hline F7 & $3.74 \pm 0.02$ & $5.42 \pm 0.03$ & $0.57 \pm 0.04$ & $329.2 \pm 1.4$ & $97.19 \pm 0.002$ \\
\hline F9 & $3.69 \pm 0.05$ & $5.72 \pm 0.05$ & $0.53 \pm 0.06$ & $331.4 \pm 1.2$ & $98.28 \pm 0.002$ \\
\hline
\end{tabular}

Table 4: Buoyancy studies of formulations

\begin{tabular}{lll}
\hline Formulation code & FLT (seconds) & Floating duration (hrs) \\
\hline F1 & 52 & $>12$ \\
F2 & 58 & 10 \\
F3 & 76 & 10 \\
F4 & 29 & 7 \\
F5 & 36 & 8 \\
F6 & 34 & 8 \\
F7 & 34 & $>12$ \\
F8 & 32 & $>12$ \\
F9 & 39 & $>12$ \\
\hline
\end{tabular}

FLT: Floating lag time

Carbopol 934, HPMC K100M, xanthan gum, and mixture of drug with the above polymers were taken and compared. The FTIR spectrum of venlafaxine hydrochloride reveal the presence of peaks at 2939.6 due to the presence of $\mathrm{C}-\mathrm{H}$ stretching, at 1647.2 due to the presence of $\mathrm{C}=\mathrm{C}$ aromatic stretching, at 3349.5 due to the presence of $\mathrm{O}-\mathrm{H}$ stretching, 1243.16 due to the presence of C-0 stretching, 3349.5 due to the presence of $\mathrm{N}-\mathrm{H}$ stretching, 1308 due to the presence of $\mathrm{C}-\mathrm{N}$ stretching. Major frequencies of functional groups of the pure drug remain intact in a powder containing Carbopol 934, HPMC K100M and xanthan gum. Hence, there is no major interaction between the drug and polymers used in the study.

\section{Pre compression parameters}

Floating tablets of venlafaxine hydrochloride were developed to increase the gastric residence time of the drug so that they can be retained in the stomach for longer time and help in the controlled release of drug up to $12 \mathrm{hrs}$ [36]. Different grades of viscosities of the polymers such as Carbopol 934, xanthan gum, HPMC K100M are known to be beneficial in improving floating property and release characteristics. The precompression parameters obtained for all formulations are tabulated in Table 2. The value of the angle of repose indicates good flow property of powder blend. Carr's index value indicates that the powder blend has the required flow property for direct compression.

\section{Post compression parameters}

The floating tablets were prepared by direct compression method using the polymers Carbopol 934, xanthan gum, HPMC K100M to provide sufficient drug release retardation and provide sufficient buoyancy to the tablets. The results are shown in Table 3. The prepared floating tablets were evaluated for thickness, hardness, friability, average weight variation, drug content, all the studies were performed in triplicates, and the results were expressed in \pm standard deviation. The hardness for the tablets ensures the good handling characteristics of all the batches. The percentage friability was $<1 \%$ in all the formulations ensuring that the tablets were mechanically stable. The weight variation for different formulations was found to be in the acceptable limit. The drug content uniformity in all the formulations was calculated and the presence of the active ingredient was found to be $97.19-98.45 \%$, with low standard deviation indicates batch-to-batch consistency.

\section{Swelling index}

Swelling index for all the formulations was carried out in the distilled water and simulated gastric fluid $(0.1 \mathrm{~N} \mathrm{HCl})$. It was found that the formulation showed rapid uptake of distilled water whereas there was gradual constant uptake of simulated gastric fluid (Fig. 1). The tablets containing Carbopol 934 and HPMC K100M showed maximum swelling in $12 \mathrm{hrs}$ with a sharp increase up to $8 \mathrm{hrs}$ which may be due to increased concentration of HPMC K100M which retain water and form a thick swollen mass.

\section{Buoyancy studies}

The in vitro floating behavior of the tablets was studied by placing them in beaker containing $0.1 \mathrm{~N} \mathrm{HCl}(\mathrm{pH} 1.2)$. The gas generating agents immediately evolves carbon dioxide in the presence of $\mathrm{HCl}$ solution generating sufficient porosity which helped the dosage unit to float. Formulation F1-F3 prepared with Carbopol 934 started floating after 52 seconds and remains buoyant for $10 \mathrm{hrs}$ till they were completely eroded. On the other hand, formulation F4-F6 prepared with xanthan gum which shows a floating time of $8 \mathrm{hrs}$ and formulation of F7-F9 prepared with HPMC K100M show decrease in FLT to 34 seconds and increased floating duration time to $>12 \mathrm{hrs}$. This may be due to the difference in concentration of polymers and gas generating agent [37]. This might be due to high viscosity polymer HPMC K100M maintains the integrity of the tablets for longer duration by reducing the effect of erosion thus resulting in an increase in floating time. The results are shown in Table 4. Thus, it can be concluded that the batch containing HPMC polymers showed good FLT and TFT. 
Table 5: Percentage drug release of formulations

\begin{tabular}{|c|c|c|c|c|c|c|c|c|c|}
\hline \multirow[t]{2}{*}{ Time (hrs) } & \multicolumn{9}{|c|}{ Formulations } \\
\hline & F1 & F2 & F3 & F4 & F5 & F6 & F7 & F8 & F9 \\
\hline 1 & 24.87 & 22.92 & 20.06 & 38.34 & 33.28 & 27.54 & 23.46 & 22.43 & 17.84 \\
\hline 2 & 36.24 & 33.82 & 29.71 & 52.15 & 45.38 & 38.15 & 36.87 & 31.11 & 24.18 \\
\hline 4 & 58.16 & 55.27 & 48.07 & 81.67 & 64.19 & 56.77 & 57.82 & 53.67 & 43.67 \\
\hline 6 & 76.08 & 71.18 & 69.18 & 96.44 & 81.23 & 79.26 & 72.09 & 65.28 & 61.08 \\
\hline 8 & 87.28 & 85.33 & 78.92 & 96.94 & 97.61 & 96.13 & 83.12 & 76.59 & 69.49 \\
\hline 10 & 94.79 & 91.67 & 86.13 & 97.96 & 97.92 & 98.21 & 94.65 & 88.76 & 83.54 \\
\hline 12 & 96.53 & 93.11 & 88.33 & 98.1 & 98.67 & 98.72 & 98.74 & 98.34 & 90.03 \\
\hline
\end{tabular}

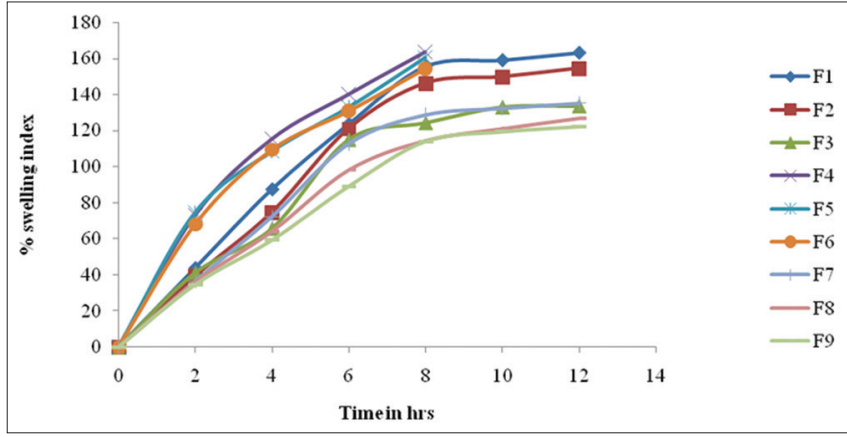

Fig. 1: Comparison of swelling index of all the formulation

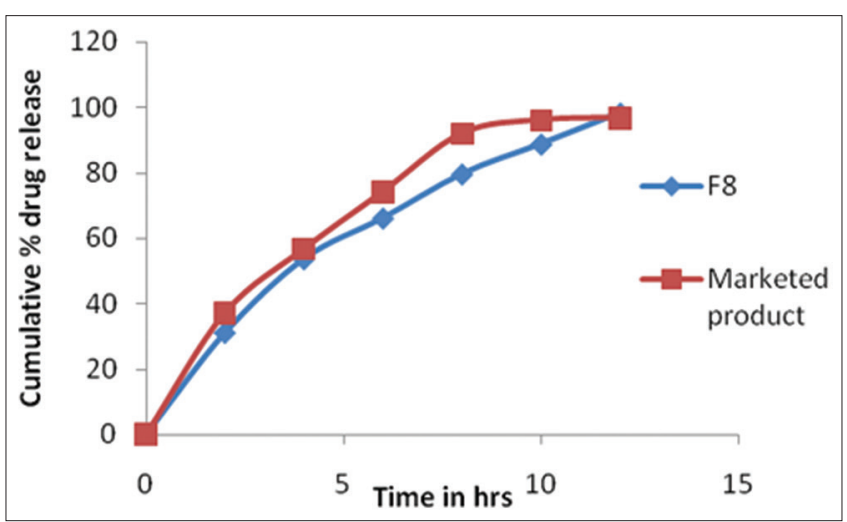

Fig. 2: Comparative studies with optimized formulation and marketed product

\section{In vitro drug release studies}

In vitro drug release studies were carried out using USP dissolution apparatus Type II at $50 \mathrm{rpm}$. The drug release at different time intervals was measured using a UV-visible spectrophotometer at $224 \mathrm{~nm}$. To check the $100 \%$ dissolution release profile, formulations were subjected to dissolution studies for $12 \mathrm{hrs}$. Among the nine formulations, F8 was best and shows $98.34 \%$ drug release in the end of $12 \mathrm{hrs}$. It is evident from the in vitro dissolution data that increase in HPMC K100M concentration decreases the release rate which might be due to increase in diffusional path length, which the drug molecule may have to travel. It also indicates that higher viscosity of the polymer concentrations greatly retard the release of drug. Hence, formulation F8 was selected as the optimized formulation. The results are shown in Table 5 .

\section{Release kinetics}

The in vitro drug release data of the floating tablets were evaluated kinetically by zero order kinetics; first order kinetics, Higuchi plot, and Peppa's models. The regression coefficient $\left(\mathrm{R}^{2}\right)$ value for zero order, first order, Higuchi's, and Peppa's plots for optimized formulation F8 was found to be $0.959,0.953,0.998,0.987$ (Table 6). The optimized formulation F8 follows Higuchi's plot since the regression coefficient
Table 6: Correlation coefficients of different mathematical models for F-1 to F-9

\begin{tabular}{llllll}
\hline Formulation & \multirow{2}{*}{$\begin{array}{l}\text { Zero } \\
\text { order } \mathbf{R}^{2}\end{array}$} & $\begin{array}{l}\text { First } \\
\text { order } \mathbf{R}^{2}\end{array}$ & $\begin{array}{l}\text { Higuchi } \\
\mathbf{R}^{2}\end{array}$ & \multicolumn{2}{l}{ Peppas } \\
\cline { 5 - 6 } & & & $\mathbf{R}^{2}$ & N value \\
\hline F1 & 0.891 & 0.938 & 0.961 & 0.964 & 0.612 \\
F2 & 0.912 & 0.947 & 0.984 & 0.972 & 0.579 \\
F3 & 0.934 & 0.979 & 0.987 & 0.987 & 0.586 \\
F4 & 0.830 & 0.872 & 0.857 & 0.878 & 0.457 \\
F5 & 0.886 & 0.907 & 0.893 & 0.885 & 0.466 \\
F6 & 0.898 & 0.926 & 0.935 & 0.959 & 0.569 \\
F7 & 0.925 & 0.947 & 0.990 & 0.985 & 0.669 \\
F8 & 0.959 & 0.953 & 0.998 & 0.987 & 0.660 \\
F9 & 0.974 & 0.958 & 0.995 & 0.982 & 0.716 \\
\hline
\end{tabular}

Table 7: Stability studies of optimized formulation F8

\begin{tabular}{|c|c|c|c|c|}
\hline \multirow[t]{2}{*}{ Time (days) } & \multicolumn{4}{|c|}{$\begin{array}{l}25^{\circ} \mathrm{C} \pm 2^{\circ} \mathrm{C} / 60 \% \mathrm{RH} \pm 5 \% \mathrm{RH}, 30^{\circ} \mathrm{C} \pm 2^{\circ} \mathrm{C} / 65 \% \\
\mathrm{RH} \pm 5 \% \mathrm{RH}, 40^{\circ} \mathrm{C} \pm 2^{\circ} \mathrm{C} / 75 \% \mathrm{RH} \pm 5 \% \mathrm{RH}\end{array}$} \\
\hline & $\begin{array}{l}\text { Hardness } \\
\left(\mathrm{kg} / \mathrm{cm}^{2}\right)\end{array}$ & $\begin{array}{l}\text { Drug } \\
\text { content (\%) }\end{array}$ & $\begin{array}{l}\% \text { Drug } \\
\text { release }\end{array}$ & TFT \\
\hline 30 & 5.56 & 98.45 & 98.34 & $>12$ \\
\hline 60 & 5.56 & 98.42 & 98.27 & $>12$ \\
\hline 90 & 5.48 & 98.18 & 98.71 & $>12$ \\
\hline
\end{tabular}

TFT: Total floating time

is 0.998 and were found to be linear, which indicates that the drug release depended on the square root of the time and predominantly controlled by diffusion process. The mechanism of drug release is predicted using Korsmeyer-Peppas equation. The $n$ value of optimized formulation F8 is 0.66 . This indicates that the drug release depends on swelling, diffusion, and erosion. All formulations follow then on - Fickian/anomalous type of diffusion.

\section{Stability studies}

Stability studies were carried out on selected formulations (F8) as per ICH guidelines. There was not much variation in matrix integrity of the tablets at all the temperature conditions. There were no significant changes in drug content, physical stability, hardness, friability, drug release, FLT (Table 7) for the selected formulation F8 after 90 days.

\section{Comparison with marketed product}

The marketed product released $96.16 \%$ drug in $10 \mathrm{hrs}$, whereas the optimized formulation F8 released $98.3 \%$ of drug in $12 \mathrm{hrs}$. Thus, comparative study of the marketed product of venlafaxine hydrochloride showed that the optimized formulation F8 has better control over release rate when compared with the commercial product (Fig. 2).

\section{CONCLUSION}

FDDS are retained in the stomach for a longer time and assist in improving the oral controlled delivery of drugs that have an absorption window in the particular region of the GIT as well as for controlling 
the release of the drug having site-specific absorption limitation. Venlafaxine hydrochloride, an antidepressant drug exhibits $\mathrm{pH}$ dependent solubility. Hence, an attempt was made to develop gastro retentive delivery system of venlafaxine hydrochloride which increased the bioavailability of venlafaxine hydrochloride and also to reduce the frequency of administration, thereby improving patient compliance and therapeutic efficacy.

In the present study, formulations F1-F9 were prepared by direct compression. The dissolution studies were carried out for $12 \mathrm{hrs}$. When compared to other formulations, F8 showed good FLT and TFT. Based on all these results, formulation F8 was selected as the optimized formulation and was compared to the marketed product. It was found that the optimized formulation F8 has better control over release rate in comparison to the commercial product. The drug-polymer ratios, viscosity of polymers, were found to influence the drug release and floating properties of the prepared tablets. From the results, it can be concluded that as the concentration of the polymer increased FLT decreased and the percentage drug release was prolonged. Viscosity of the polymer also showed a directly proportional relationship with swelling characteristics of the tablets. The optimized formulation (F8) was subjected for stability studies as per ICH guidelines with no significant change in the various evaluated parameters of the formulations. Overall, this study concludes that viscosity is a major factor affecting the release and floating properties of the gastric floating drug delivery system [38]. The use of hydrophobic retardant and hydrophilic polymer in combination had its own advantages of maintaining integrity and buoyancy of tablets. And also in initial burst effect was minimized. It could be concluded that for proper floating duration and in vitro release, the hydrophobic retardant and hydrophilic polymer must be used in proper ratio [38].

\section{REFERENCES}

1. Sood A, Panchagnula R. Design of controlled release delivery system using a modified pharmacokinetic approach, a case study for drugs having a short elimination half-life and a narrow therapeutic index. Int J Pharm 2003;261:27-41.

2. Vyas SP, Khar RK. Gastro Retentive Systems in Controlled Drug Delivery, Concepts and Advances. 1st ed. New Delhi: CBS Publications; 2002. p. 196-217.

3. Chickering DE, Jacob JS, Mathowitze E. Bioadhesive microspheres characterization and evaluation of bioadhesion involving hard, erodible polymers and soft tissues. React Polym 1995;25:189-206.

4. Garg S, Sharma S. Review-gastro retentive drug delivery system. Pharm Technol 2003;13:160-6.

5. Garg S, Sharma S. Gastro retentive drug delivery systems. Bus Brief Pharm Technol 2003;3:160-6.

6. Narang N. An updated review on floating drug delivery system (FDDS). Int J Appl Pharm 2011;3(1):1-7.

7. Koner P, Saudagar RB, Dharwal J. Gastro-Retentive Drugs a Novel Approach Towards Floating Therapy. Available from: http//www. pharma info.net/ exclusive/ reviews/ gastro retentive drugs a novel approach towards floating therapy/2007.

8. Tayade P. Gastro retentive drugs. A review. Express Pharm Pulse 2003;14:1-4.

9. Hilton AK, Deasy PB. In vitro and in vivo evaluation of oral sustained release floating dosage forms of amoxillintrihydrate. Int $\mathrm{J}$ Pharm 1992;86:79-88.

10. Sheth PR, Tossounian J. The hydrodynamically balanced system (HBSTN). A novel drug delivery system for oral use. Drug Dev Ind Pharm 1984;10:313-39.

11. Rubinstein A, Friend DR. Specific delivery to the gastrointestinal tract. In: Domb AJ, editor. Polymeric Site-Specific Pharmacotherapy. Chichester: Wiley; 1994. p. 282-3.

12. Ritschel WA. Targeting in the gastrointestinal tract: New approaches. Methods Find Exp Clin Pharmacol 1991;13(5):313-36.
13. Michaels AS, Bashwa JD, Zaffaroni A Integrated Device for Administering Beneficial Drug at Programmed Rate. US Patent 3, 901, 232 August 26; 1975.

14. Michaels AS. Drug Delivery Device with Self-actuated Mechanism for Retaining Device in Selected Area. US Patent 3, 786, 813, January $22 ; 1974$.

15. Keith S. Advances in psychotropic formulations. Prog Neuropsychopharmacol Biol Psychiatry 2006;30:996-1008.

16. Dickson RB, Hardik T, Bhai R, Sureshkumar P, Jamsheer AK, Senthil A. Formulation and evaluation of gastro retentive floating tablet of glipizide. Int J Res Ayurveda Pharm 2011;2(3):911-7.

17. Liu L, Porter WR. Developing Solid Oral Dosage Forms: Pharmaceutical Theory and Practice. Ch. IV. USA, London: Academic Press; 2008. p. 125-35.

18. Pare A, Yadav SK, Patil UK. Formulation and evaluation of effervescent floating tablet of amlodipine besylate. Res J Pharm Technol 2008;1(4):526-30.

19. Peck GE, Baley GJ, McCurdy VE, Banker GS. Tablet Formulation and Design. New York: Marcel Dekker, Inc.; 1989. p. 88-120.

20. Liberman HA, Lachman L, Schwartz JB. Pharmaceutical Dosage Forms: Tablets. Vol. 1. New York: Marcel Dekker, Inc.; 1989. p. 1-5.

21. Shah D, Shah Y, Rampradhan M. Development and evaluation of controlled release diltiazem hydrochloride, micro particles using cross linked poly vinyl alcohol. Drug Dev Ind Pharm 1997;23:557-64.

22. Cooper J, Gunn C. Powder flow and compaction. Tutorial Pharmacy. New Delhi: CBS Publishers and Distributors; 1986. pp. 211-3.

23. Aulton ME, Wells TI. Pharmaceutics: The Science of Dosage form Design. London: Churchill Livingstone; 1998, p. 247-8.

24. Lachman L, Liberman HA, Konig JL. The Theory and Practice of Industrial. Philadelphia, PA: Pharmacy Leo \& Febiger; 1987. p. 317-8.

25. Singh S, Prajapati K, Pathak AK, Mishra A. Formulation and evaluation of floating tablet of captopril. Int $\mathrm{J}$ Pharm Techol Res 2011;3(1):333-41

26. Aulton ME. Pharmaceutics: The Science of Dosage Forms Design. 2nd ed. London: Churchill Livingstone; 1988.

27. Liu L, Porter WR. Developing Solid Oral Dosage Forms: Pharmaceutical Theory and Practice. Ch. IV. USA, London: Academic Press; 2008. p. $125-35$.

28. Patel VM, Prajapati BG, Patel AK. Controlled release gastroretentive dosage form of verpamil hydrochloride. Int J Pharm Technol Res 2009;1(2):215-21

29. Rosa M, Zia H, Rhodes T. Dosing and testing in vitro of a bio adhesive and floating drug delivery system for oral application. Int J Pharm 1994;105:65-70.

30. Patel DM, Patel NM, Pandya NN, Jogani PD. Gastro retentive drug delivery system of carbamazepine: Formulation and optimization using simplex lattice design; A technical note. AAPS Pharm Sci Technol 2001;8(1):11, E1-5.

31. Pandit V, Suresh S, Joshi H. Gastro retentive drug delivery system of amoxicillin: Formulation and in vitro evaluation. IJPBS 2010;1(2):1-10.

32. Wagner JG. Interpretation of percentage dissolved time plots derived from in vitro testing of conventional tablets and capsules. J Pharm Sci 1969;58:1253-7.

33. Higuchi T. Mechanism ODF sustained action medication, theoretical analysis of rate of release of solid drugs dispersed in solid matrices. J Pharm Sci 1963;52:1145-9.

34. Koresmeyer R, Gurny R, Peppas N. Mechanisms of solute release from porous hydrophilic polymers. Int J Pharm 1983;15:25-35.

35. ICH Stability Testing Guidelines: Stability Testing of New Drug Substances and Products.

36. Mohideen S, Kumar PS, Krishnan SN, Ayana TS, Shaji G, Surendranath Y, et al. Formulation and evaluation of gastroretentive floating tablets of venlafaxine hydrochloride. Int J Pharm Pharm Sci 2012;4(2):329-3

37. Ananthakumar R, Raja N, Mohan P, Ruckmani K. Design and evaluation of intragastric buoyant tablets of metformin hydrochloride. Int J Pharm Pharm Sci 2013;5(3):479-84.

38. Pawar HA, Dhavale R. Development and evaluation of gastro retentive floating tablets of an antidepressant drug by thermoplastic granulation technique. Beni Suef Univ J Basic and Appl Sci 2014;3(2):122-32. 